\title{
Synthesis and Spectral Studies of Ni(II) Dithiocarbamate Complexes and Their Use as Precursors for Nickel Sulphides Nanocrystals
}

\author{
Azile Nqombolo and Peter A. Ajibade \\ Department of Chemistry, University of Fort Hare, Private Bag Box X1314, Alice 5700, South Africa \\ Correspondence should be addressed to Peter A. Ajibade; pajibade@ufh.ac.za
}

Received 15 July 2016; Revised 13 September 2016; Accepted 20 September 2016

Academic Editor: Henryk Kozlowski

Copyright (C) 2016 A. Nqombolo and P. A. Ajibade. This is an open access article distributed under the Creative Commons Attribution License, which permits unrestricted use, distribution, and reproduction in any medium, provided the original work is properly cited.

\begin{abstract}
$\mathrm{Ni}$ (II) dithiocarbamate complexes have been synthesized and characterized by UV-Vis, FTIR, and NMR spectroscopic techniques. Electronic spectra measurements indicate that the complexes are four-coordinate square planar geometry while the FTIR confirmed that the dithiocarbamates act as bidentate chelating ligands. The compounds were used as single source precursors and thermolysed at $220^{\circ} \mathrm{C}$ to prepare $\mathrm{HDA}$-capped $\mathrm{NiS}$ nanocrystals which were characterized by absorption and photoluminescence (PL) spectra measurements, powder X-ray diffraction (PXRD), transmission electron microscopy (TEM), scanning electron microscopy (SEM), and energy dispersive spectroscopy (EDS). Absorption spectra studies showed that the synthesized NiS nanoparticles are blueshifted relative to the bulk material and PL studies showed emission maxima that are red-shifted compared to the absorption band edges. The XRD patterns of the as-prepared NiS nanoparticles revealed cubic crystalline phases. TEM images showed spherical and close-to-spherical nanocrystals with the size in the range 12-38 nm for NiS1, 8-11 nm for NiS2, and 9-16 nm for NiS3. SEM images showed homogeneous surface morphology and EDS confirmed the presence of Ni and S and the formation of NiS nanoparticles.
\end{abstract}

\section{Introduction}

In recent years, nanomaterials have received considerable attention and are being widely studied because of their size dependent properties that give rise to application in fields such as catalysis [1, 2], agriculture [3], or solar cells [4]. Different methods such as sputtering $[5,6]$, coprecipitation [7], sol-gel method [8], microemulsion [9], hydrothermal technique [10], and single source precursors [11] have been used for the preparation of metal sulphide nanoparticles. In spite of the numerous methods, the challenge in the development of materials with novel optical and structural properties remains getting uniform shapes and sizes. Thus, single source precursors are being used to prepare metal sulphide nanoparticles and thin films since they offer the advantage of one-pot synthesis with uniform size distributions [12-16].

Single source precursors have been employed to prepare NiS nanocrystals and this has resulted in particles with varying crystalline phases and sizes [17-20]. Salavati-Niasari et al. reported the synthesis of nickel sulphide nanoparticles by the hydrothermal method in the presence of thioglycolic acid. The XRD patterns showed $\beta$-NiS and the optical studies showed that the as-prepared nanoparticles were blue-shifted compared to the bulk nickel sulphide $(\sim 2.1 \mathrm{eV})$ [17]. $\beta$-NiS nanoparticles have also been reported by Nagaveena et al. with peaks indexed to rhombohedral structure [18] while Wang et al. reported pure orthorhombic phase of nickel sulphide nanoparticles using the sonochemical method, and the TEM images revealed spherically shaped nanoparticles [19]. It has also been reported that NiS nanoparticles prepared by Yuan and Luan [20] using the solvothermal method showed nanoparticles with hexagonal NiS, cubic $\mathrm{NiS}_{2}$, orthorhombic $\mathrm{Ni}_{7} \mathrm{~S}_{6}$, and trigonal $\mathrm{Ni}_{3} \mathrm{~S}_{2}$ crystalline phases [20]. In other studies, patch-like structures of NiS nanoparticles were obtained based on the morphological studies from SEM images [21]. The variation in size and shapes of the nanocrystals obtained indicates that there is still 
a need to develop robust methods that might give nanocrystals with the desired shapes and sizes. In this study, we present the synthesis and spectroscopic characterization of $\mathrm{Ni}$ (II) dithiocarbamate complexes and their thermal decomposition to prepare NiS nanocrystals. The optical, structural, and morphological properties of the as-prepared nanocrystals were studied with absorption and emission spectroscopy, powder X-ray diffraction (PXRD), transmission electron microscopy (TEM), scanning electron microscopy (SEM), energy dispersive spectroscopy (EDS).

\section{Material and Methods}

2.1. Materials. Materials used included anisidine, dibenzylamine, butylamine, carbon disulphide, potassium hydroxide, ethanol, methanol, diethyl ether, nickel(II) chloride, and acetone. All chemicals and reagents used were of analytical grade and were used as obtained without further purification.

2.2. Characterization. A Perkin Elmer Lambda 25 UV-Vis spectrophotometer was employed to carry out optical measurements at room temperature. The photoluminescence of the nanoparticles was measured using Perkin Elmer LS 45 fluorimeter. Powder X-ray diffraction patterns were recorded on Bruker-D8 Advance powder X-ray diffractometer instrument operating at a voltage of $40 \mathrm{kV}$ and a current of $30 \mathrm{~mA}$ with $\mathrm{Cu}$ $\mathrm{K} \alpha$ radiation. The $\mathrm{X}$-ray diffraction data were analysed using EVA (evaluation curve fitting) software. Phase identification was carried out with the help of standard JCPDS database. The transmission electron microscopy (TEM) images were obtained using a Zeiss Libra 120 electron microscope operated at $120 \mathrm{kV}$. The samples were prepared by placing a drop of sample solution in toluene on a carbon coated copper grid (300-mesh, agar). Images were recorded on a MegaView G2 camera using iTEM Olympus software. The scanning electron microscopy (SEM) images were obtained on a Jeol JSM-6390 LV apparatus, using an accelerating voltage between 15 and $20 \mathrm{kV}$ at different magnifications. Energy dispersive spectra were processed using energy dispersive spectroscopy (EDS) attached to a Jeol JSM-6390 LV SEM with Noran System SIX software.

\subsection{Syntheses}

2.3.1. Synthesis of Potassium Salt of the Ligands. The ligands, potassium salt of anisidine dithiocarbamate $\left(\mathrm{KL}^{1}\right)$, dibenzyl dithiocarbamate $\left(\mathrm{KL}^{2}\right)$, and butyl dithiocarbamate $\left(\mathrm{KL}^{3}\right)$, were prepared as follows.

$5 \mathrm{mmol}$ of anisidine $(6.16 \mathrm{~g})$, dibenzylamine $(10 \mathrm{~mL})$, and butylamine $(5 \mathrm{~mL})$ reacted with $5 \mathrm{mmol}$ of potassium hydroxide $(2.18 \mathrm{~g})$ in a conical flask placed in ice water and stirred, after which $5 \mathrm{mmol}(3 \mathrm{~mL})$ of cold carbon disulphide was added dropwise. The temperature of the reaction mixture was maintained below $4^{\circ} \mathrm{C}$ for about 3-4 hours. The resulting product was filtered, washed with diethyl ether, and then recrystallized in acetonitrile and dried.

$\mathrm{KL}^{1}$ : Yield: 3.49 g, $97 \%$, M.p. $94^{\circ} \mathrm{C}$, IR $\left(\mathrm{KBr}, \mathrm{cm}^{-1}\right)$ : $1504(\nu \mathrm{C}-\mathrm{N}), 1296(\nu \mathrm{C}=\mathrm{S}), 1035(\nu \mathrm{C}-\mathrm{S}){ }^{1} \mathrm{H}-\mathrm{NMR}$ $\left(\mathrm{dmso}^{-\mathrm{d}_{6}}\right) \delta(\mathrm{ppm})=2.5(\mathrm{~s}, 1 \mathrm{H})$ for $-\mathrm{CH}-$ proton of the ring, $9.80(\mathrm{~s}, 1 \mathrm{H}) \mathrm{N}-\mathrm{H}$ proton, $6.76-7.38(\mathrm{~d}, 2 \mathrm{H})$ for $=\mathrm{CH}-\mathrm{CH}=$ protons of aromatic ring.

$\mathrm{KL}^{2}$ : Yield: 3.91 g, $91 \%$, M.p. $98^{\circ} \mathrm{C}$, IR $\left(\mathrm{KBr}, \mathrm{cm}^{-1}\right): 1516$ $(\nu \mathrm{C}-\mathrm{N}), 1252(\nu \mathrm{C}=\mathrm{S}), 1000(\nu \mathrm{C}-\mathrm{S}){ }^{1} \mathrm{H}-\mathrm{NMR}$ (dmso$\left.\mathrm{d}_{6}\right) \delta=7.23-7.21(\mathrm{~m}, 5 \mathrm{H})$ for $-\mathrm{C}_{6} \mathrm{H}_{5}$ protons from the aromatic ring, $5.30(\mathrm{~d}, 2 \mathrm{H})$ for ethyl protons.

$\mathrm{KL}^{3}$ : Yield: $8.32 \mathrm{~g}, 90 \%$, M.p. $67^{\circ} \mathrm{C}$, IR $\left(\mathrm{KBr}, \mathrm{cm}^{-1}\right)$ : $1470(\nu \mathrm{C}-\mathrm{N}), 1159(\nu \mathrm{C}=\mathrm{S}), 1015(\nu \mathrm{C}-\mathrm{S}){ }^{1} \mathrm{H}-\mathrm{NMR}$ $\left(\mathrm{dmso}_{6} \mathrm{~d}_{6}\right) \delta=0.83(\mathrm{t}, 3 \mathrm{H})-\mathrm{CH}_{3}, 0.92-1.26(\mathrm{~m}, 5 \mathrm{H})$ $-\mathrm{CH}_{2}, 7.8(\mathrm{~s}, 1 \mathrm{H}) \mathrm{N}-\mathrm{H}$ protons.

2.3.2. Synthesis of Ni(II) Dithiocarbamate Complexes. $5 \mathrm{mmol}$ $(0.45 \mathrm{~g})$ of potassium salts of anisidine dithiocarbamate, dibenzyl dithiocarbamate $(0.57 \mathrm{~g})$, and butyl dithiocarbamate $(0.43 \mathrm{~g})$ ligands was dissolved in $10 \mathrm{~mL}$ of methanol in a beaker. $2.5 \mathrm{mmol}(0.59 \mathrm{~g})$ of $\mathrm{NiCl}_{2}$ was dissolved in methanol in a separate beaker. The two solutions were mixed and stirred for 1-3 hours. The resulting product was filtered and washed with water followed by diethyl ether and dried. The complexes are labelled as $\left[\mathrm{Ni}\left(\mathrm{L}^{1}\right)_{2}\right]$ from anisidine dithiocarbamate, $\left[\mathrm{Ni}\left(\mathrm{L}^{2}\right)_{2}\right]$ from dibenzyl dithiocarbamate, and $\left[\mathrm{Ni}\left(\mathrm{L}^{3}\right)_{2}\right]$ from butyl dithiocarbamate ligand.

[Ni $\left.\left(\mathrm{L}^{1}\right)_{2}\right]$ : Yield: 3.22 g, 49\%, M.p. $201^{\circ} \mathrm{C}$, IR (KBr, $\left.\mathrm{cm}^{-1}\right)$ : $1571(\nu \mathrm{C}-\mathrm{N}), 1131$ ( $\left.\nu \mathrm{C}-\mathrm{S}\right), 460(\mathrm{Ni}-\mathrm{S})$.

[Ni $\left(\mathrm{L}^{2}\right)_{2}$ ]: Yield: 1.35 g, $60 \%$, M.p. $200^{\circ} \mathrm{C}$, IR (KBr, $\left.\mathrm{cm}^{-1}\right): 1593(\nu \mathrm{C}-\mathrm{N}), 1234(\nu \mathrm{C}-\mathrm{S}), 495(\mathrm{Ni}-\mathrm{S})$.

[Ni( $\left.\left.\mathrm{L}^{3}\right)_{2}\right]$ : Yield: $1.48 \mathrm{~g}, 49 \%$, M.p. $139^{\circ} \mathrm{C}$, IR (KBr, $\left.\mathrm{cm}^{-1}\right): 1470(\nu \mathrm{C}-\mathrm{N}), 1004(\nu \mathrm{C}-\mathrm{S}), 383(\mathrm{Ni}-\mathrm{S})$.

2.4. Synthesis of NiS Nanoparticles. The nickel complexes $(0.2 \mathrm{~g})$ were dissolved in $2 \mathrm{~mL}$ tri-n-octylphosphine (TOP) and injected into $2 \mathrm{~g}$ of hot hexadecylamine (HDA) at $220^{\circ} \mathrm{C}$. The temperature was maintained for 1 hour at $220^{\circ} \mathrm{C}$. After this, the mixture was allowed to cool to $70^{\circ} \mathrm{C}$ and cold methanol was added to precipitate the NiS nanoparticles. The HDA-capped NiS nanoparticles were separated by centrifugation and washed three times with cold methanol and dried. The nanoparticles are labelled as NiS1 from nickel(II) anisidine dithiocarbamate complex $\left(\left[\mathrm{Ni}\left(\mathrm{L}^{1}\right)_{2}\right]\right)$, NiS2 from nickel(II) dibenzyl dithiocarbamate complex $\left(\left[\mathrm{Ni}\left(\mathrm{L}^{2}\right)_{2}\right]\right)$, and NiS3 from nickel(II) butyl dithiocarbamate complex $\left(\left[\mathrm{Ni}\left(\mathrm{L}^{3}\right)_{2}\right]\right)$.

\section{Results and Discussion}

3.1. FTIR Spectra Studies of the Ligands and Metal Complexes. FTIR spectra of the dithiocarbamate ligands and their corresponding complexes are presented in Figure 1. In the ligands, the $\nu \mathrm{C}-\mathrm{N}$ appeared at $1501 \mathrm{~cm}^{-1}$, for $\mathrm{KL}^{2}$ at $1515 \mathrm{~cm}^{-1}$ and for $\mathrm{KL}^{3}$ at $1470 \mathrm{~cm}^{-1}$. The observed shift in the $\nu \mathrm{C}-\mathrm{N}$ stretching frequency of complexes to higher frequency compared to that of ligands is due to the increase in the single bond character of $\nu \mathrm{C}-\mathrm{N}[22]$ due to the dominant contribution of the thioureide resonance form of the dithiocarbamate. Also, the shift in $\nu \mathrm{C}$ $\mathrm{S}$ to lower frequency in the metal complexes in comparison 

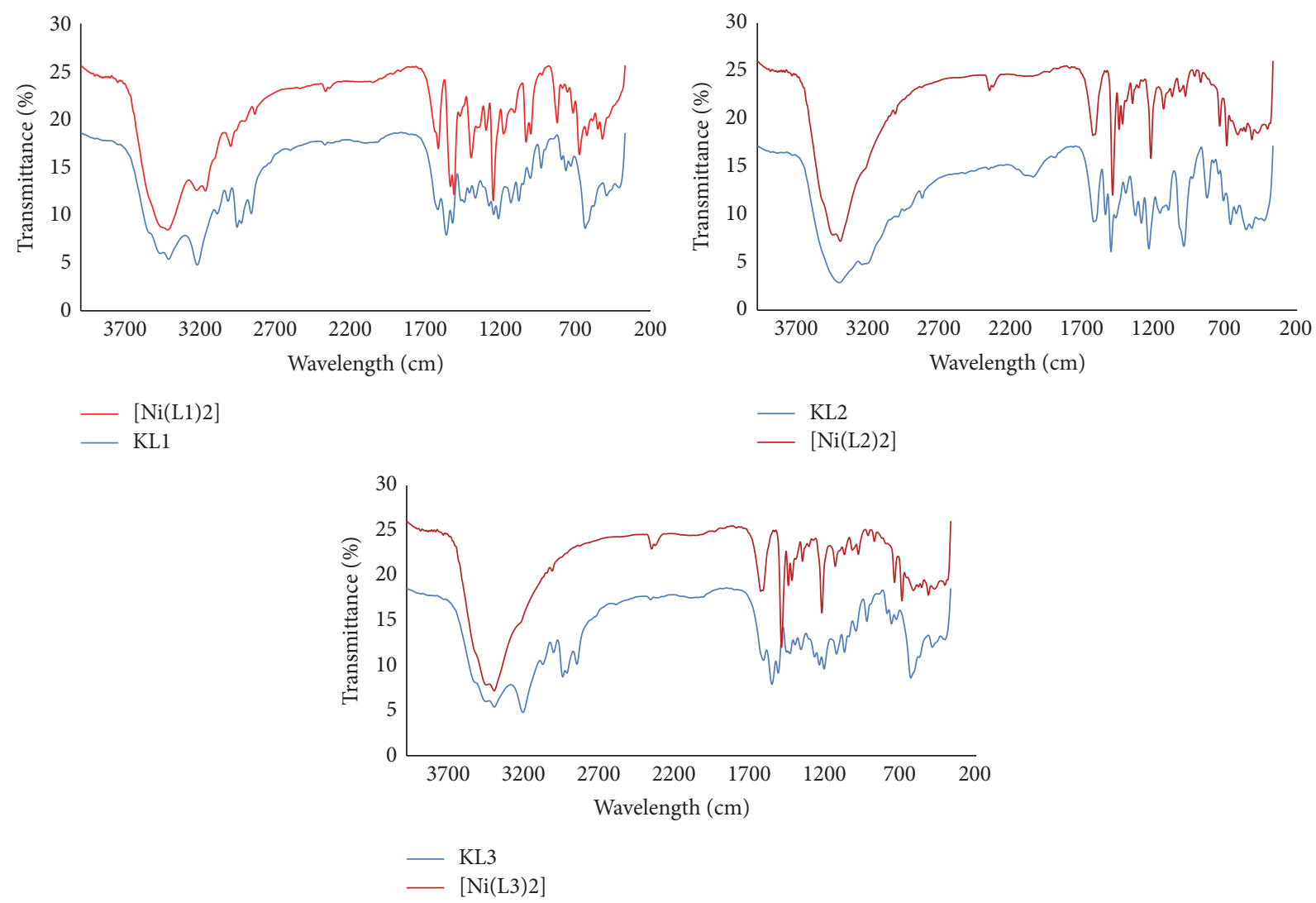

FIGURE 1: FTIR spectra of the dithiocarbamate ligands and corresponding Ni(II) complexes.

to the ligands could be ascribed to the decrease in the double bond character of $\nu \mathrm{C}=\mathrm{S}$ in the formation of the complex [23]. The $v \mathrm{Ni}-\mathrm{S}$ stretching vibration for $\left[\mathrm{Ni}\left(\mathrm{L}^{1}\right)_{2}\right]$ was observed at $470 \mathrm{~cm}^{-1}$, for $\left[\mathrm{Ni}\left(\mathrm{L}^{2}\right)_{2}\right]$ at $457 \mathrm{~cm}^{-1}$, and for $\left[\mathrm{Ni}\left(\mathrm{L}^{3}\right)_{2}\right]$ at $382 \mathrm{~cm}^{-1}$ and this confirms that the $\mathrm{Ni}$ ion is bonded to the dithiocarbamate through the sulfur atoms [24].

3.2. Electronic Spectra Studies of the Ligands and Complexes. The electronic spectra of the dithiocarbamate ligands and $\mathrm{Ni}$ (II) complexes are shown in Figure 2. Anisidine dithiocarbamate $\left(\mathrm{KL}^{1}\right)$ has an absorption band at $297 \mathrm{~nm}$ assigned to the $\pi \rightarrow \pi^{*}$ transitions of N-C-S; the second band at $303 \mathrm{~nm}$ is assigned to $\pi \rightarrow \pi^{*}$ transitions of S-C-S of dithiocarbamate moiety, and the band that appears at $305 \mathrm{~nm}$ is due to $\mathrm{n} \rightarrow \pi^{*}$ bonding which is located on the sulfur atom. In the $\mathrm{Ni}$ (II) anisidine dithiocarbamate, the intraligand charge transfer transitions occurred at $324 \mathrm{~nm}$ assigned to $\pi \rightarrow \pi^{*}$ bonding of the dithiocarbamate moiety. $\left[\mathrm{Ni}\left(\mathrm{L}^{1}\right)_{2}\right]$ has an absorption band at $418 \mathrm{~nm}$ which is assigned to the $\mathrm{d}-\mathrm{d}$ transition due to the excitation of the metal ion [25]. Dibenzyl dithiocarbamate $\left(\mathrm{KL}^{2}\right)$ has intraligand charge transfer transitions at $295 \mathrm{~nm}$ and the corresponding complex $\left[\mathrm{Ni}\left(\mathrm{L}^{2}\right)_{2}\right]$ also has intraligand charge transfer transitions but it shifted to higher wavelength at $332 \mathrm{~nm}$ and another band at 391 which is due to metal to ligand charge transfer (MLCT) transitions. At $430 \mathrm{~nm}$, there is a small band for $\mathrm{d}-\mathrm{d}$ transition observed in the $\mathrm{Ni}(\mathrm{II})$ complex. $\mathrm{KL}^{3}$ has a band at $291 \mathrm{~nm}$, which is assigned to the $\pi \rightarrow \pi^{*}$ transition of the dithiocarbamate moiety. But this band appeared as a broad absorption band at $397 \mathrm{~nm}$ in the complex, $\left[\mathrm{Ni}\left(\mathrm{L}^{3}\right)_{2}\right]$, which could be ascribed to the MLCT. At $418 \mathrm{~nm}$, there is a small band assigned to the d-d transition [25-27]. This indicates that the complex is a four-coordinate species $[25,26]$.

\subsection{Optical Studies of NiS Nanoparticles}

3.3.1. Absorption Spectra Studies of HDA-Capped NiS Nanoparticle. The absorption spectra of the NiS nanoparticles (Figure 3) showed maximum peaks at 306, 314, and $271 \mathrm{~nm}$ for NiS1, NiS2, and NiS3, respectively. The absorption band edges were used to determine the band gaps energy $\left(E_{g}\right)$ of the NiS nanoparticles [26]. The band gaps of all synthesized $\mathrm{NiS}$ nanoparticles were calculated and found to be 4.05, 3.95, and 4.58 for NiS1, NiS2, and NiS3, respectively. These were found to be blue-shifted compared to the bulk NiS [27]. This shows that the as-prepared NiS nanoparticles have very small sizes and the increase in band gaps with the decrease in particle sizes is due to quantum confinement effects in the nanoparticles [28].

3.3.2. Photoluminescence Spectra Studies of NiS Nanoparticles. The photoluminescence spectra of HDA-capped NiS nanoparticles (Figure 4) were recorded at excitation wavelength of $711 \mathrm{~nm}$. The spectra showed emission maxima at 725, 720, and $622 \mathrm{~nm}$ for NiS1, NiS2, and NiS3, respectively. 

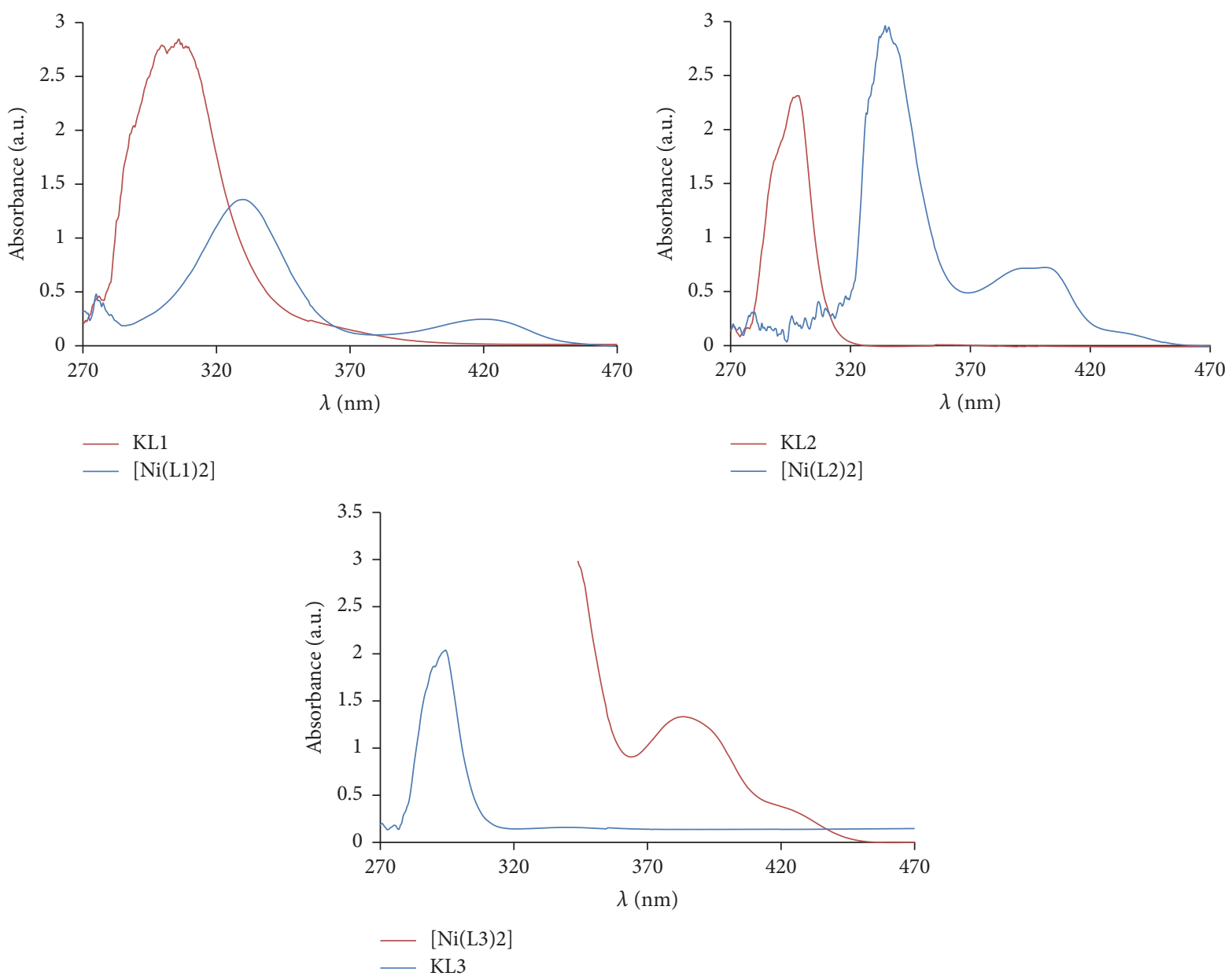

FIGURE 2: Electronic spectra of the ligands and the corresponding Ni(II) dithiocarbamate complexes.

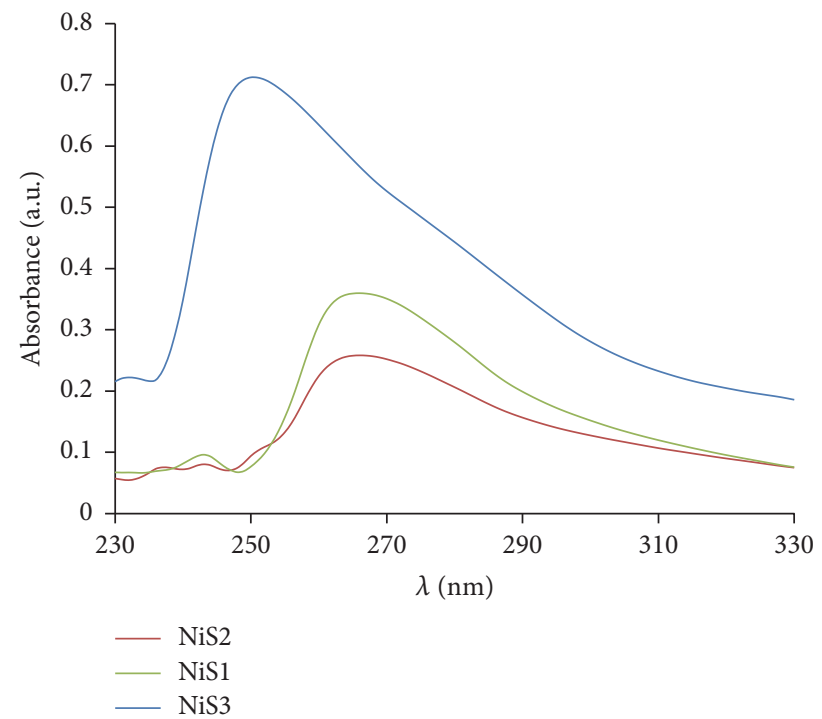

FIGURE 3: Absorption spectra of HDA-capped NiS nanoparticles.

The emission maxima were found to be red-shifted in comparison to the optical absorption band edges. The broadening

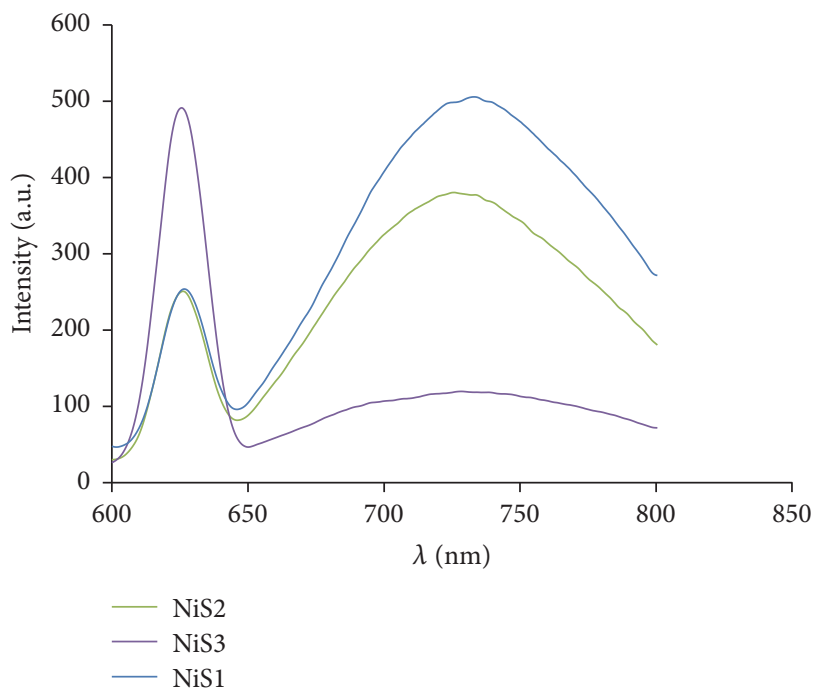

FIGURE 4: PL spectra of HDA-capped NiS nanoparticles. of the emission peaks as shown in Figure 4 could be ascribed to size distributions [29]. 

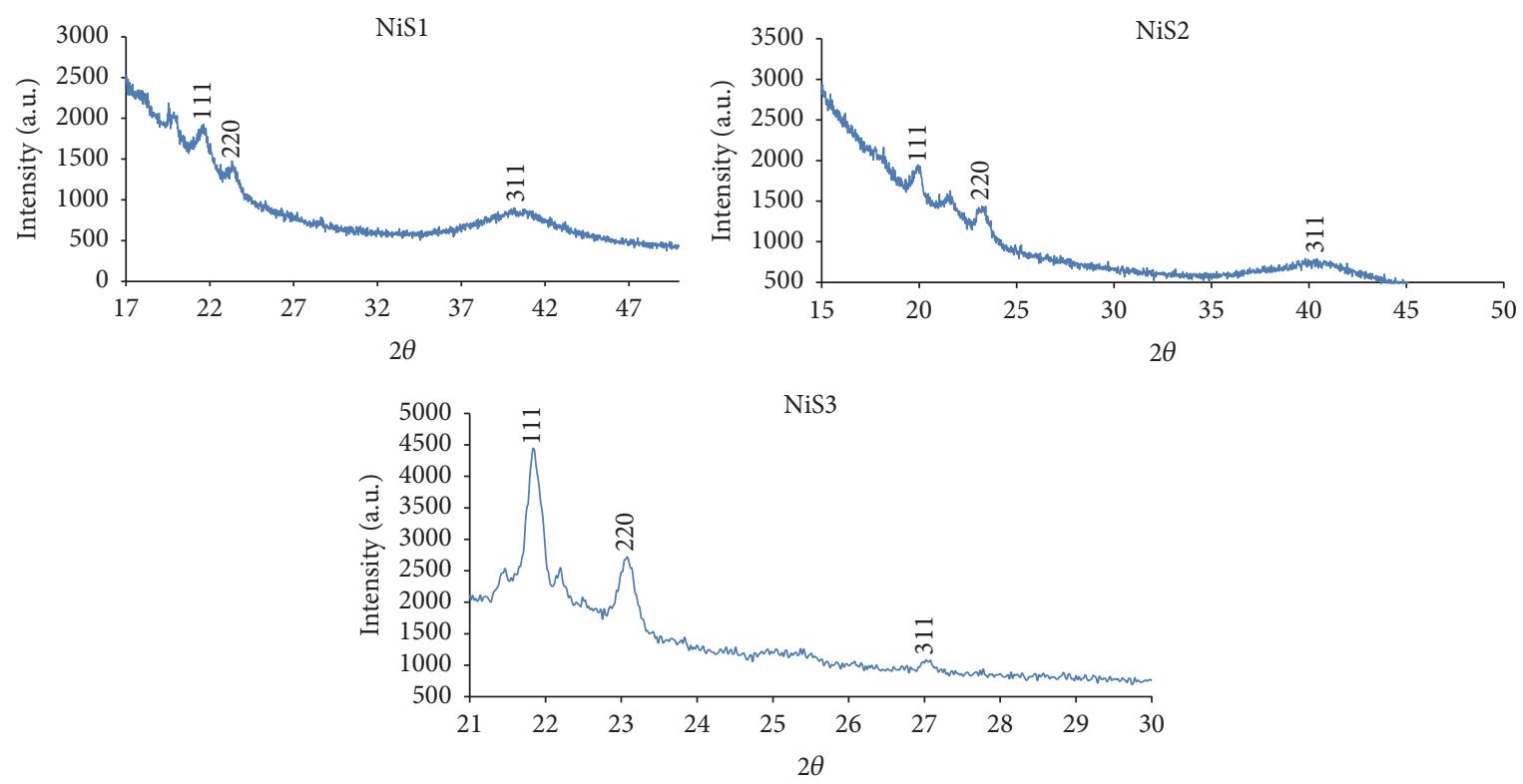

FIGURE 5: Powder XRD patterns of HDA-capped NiS nanoparticles.

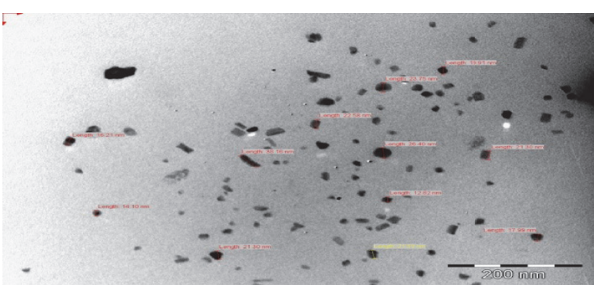

(a)

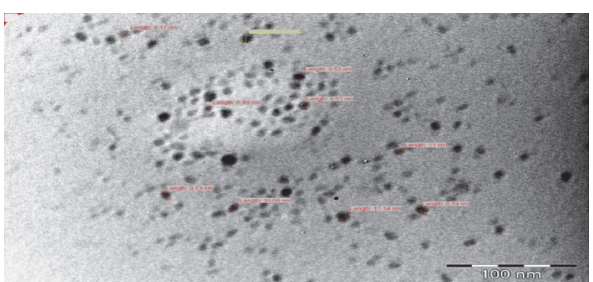

(b)

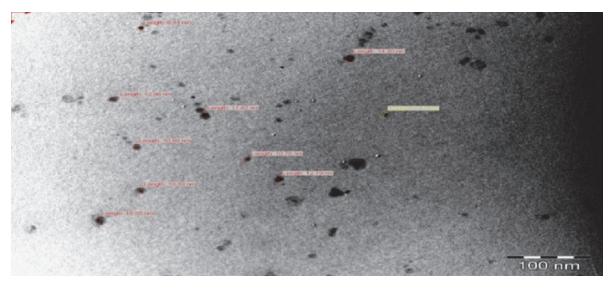

(c)

Figure 6: TEM image of NiS1 (a), NiS2 (b), and NiS3 (c).

\subsection{Structural Studies of NiS Nanoparticles}

3.4.1. XRD Pattern Studies of NiS Nanoparticles. The powder $\mathrm{X}$-ray diffraction patterns of the NiS nanoparticles are shown in Figure 5. The XRD patterns of NiS1 showed three peaks at $2 \theta$ values of $21.2^{\circ}, 22.5^{\circ}$, and $40.7^{\circ}$ which correspond to (111), (220), and (311) Miller indices for cubic NiS nanoparticles. Three peaks at $2 \theta$ values $=19.5^{\circ}, 22.7^{\circ}$, and $40.85^{\circ}$ corresponding to (111), (220), and (311) planes of cubic phase of NiS2 were observed [29]. The XRD pattern of NiS3 showed three peaks at $2 \theta$ values $=21.8^{\circ}, 22.9^{\circ}$, and $39.8^{\circ}$ which correspond to (111), (220), and (311) Miller indices of cubic NiS nanoparticles $[29,30]$. All the diffraction patterns correspond to the NiS cubic crystalline phase (ICDD card number 043-1469).
3.4.2. TEM Studies of the NiS Nanoparticles. TEM images of HDA-capped NiS nanoparticles are shown in Figure 6. TEM image of NiS1 nanoparticles showed mixture of rod-like structures and close-to-spherical shapes with uniform size distributions [29-31]. Some particles appeared elongated with some agglomeration while others are nearly spherical and triangular in shape and the particle size ranges from 12 to $38 \mathrm{~nm}$ [30]. The TEM image of NiS2 showed spherically shaped nanoparticles with little agglomeration and particle size ranging from 8 to $11 \mathrm{~nm}$. The small size is ascribed to the quantum confinement effect. The TEM image of HDAcapped NiS3 nanoparticles showed that the particles are spherical in shape with some agglomeration in between particles and the particle size ranges from 9 to $16 \mathrm{~nm}$. 

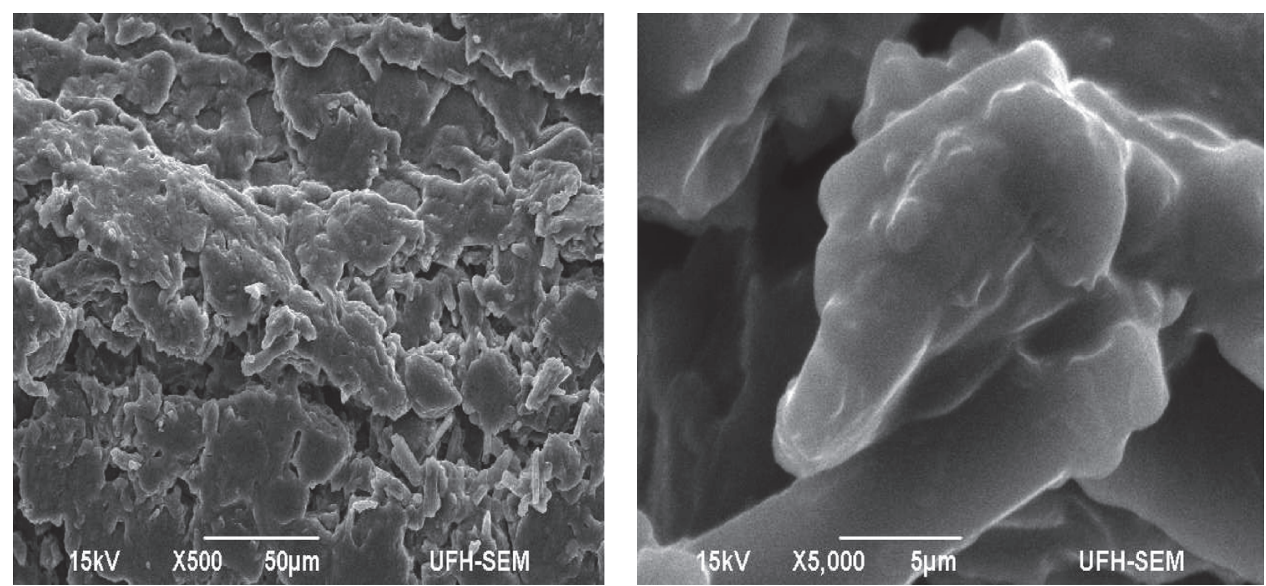

(a)
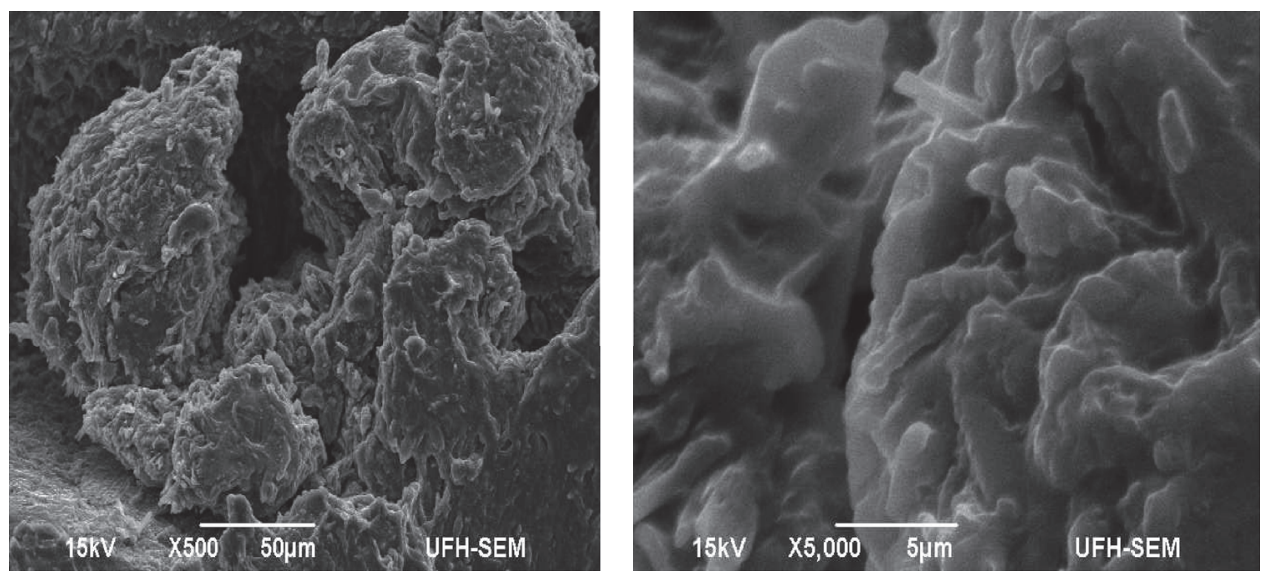

(b)
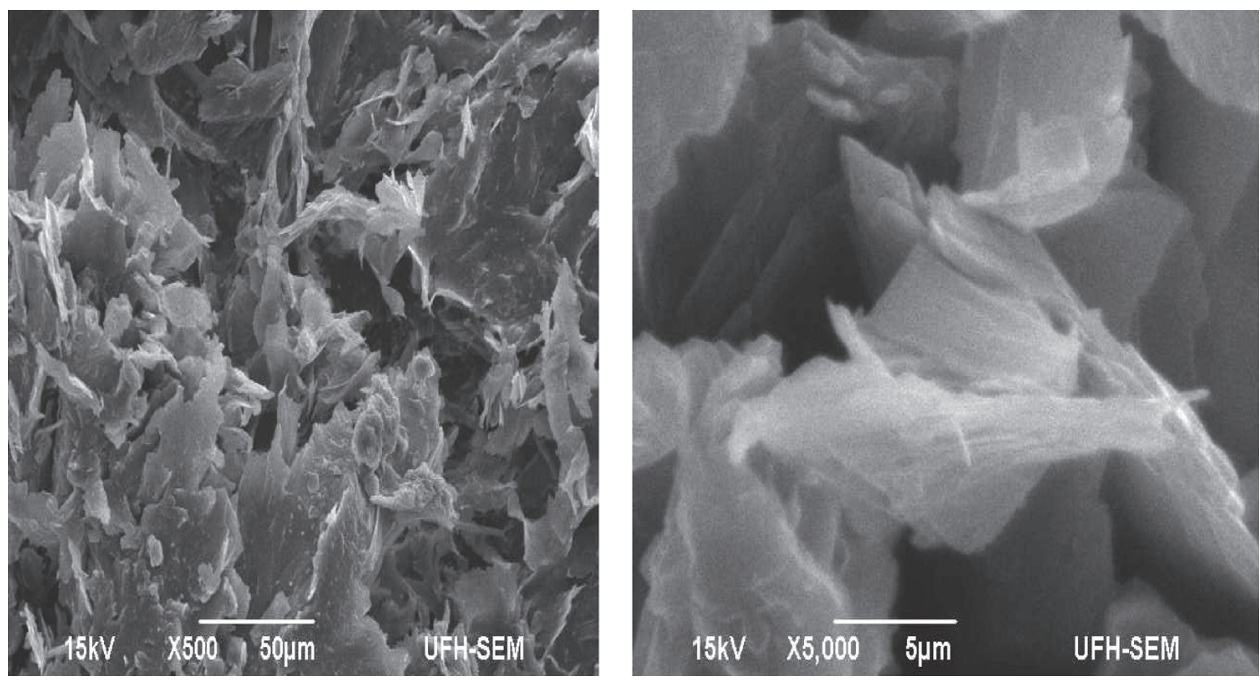

(c)

Figure 7: SEM images of NiS1 (a), NiS2 (b), and NiS (c).

3.4.3. SEM/EDS Studies of HDA-Capped NiS Nanoparticles. The scanning electron microscopy (SEM) images and energy dispersive spectroscopy (EDS) of NiS nanoparticles are shown in Figure 7. Figure 7(a) shows SEM images of NiS1 nanoparticles with particles with little or no agglomeration because the nanoparticles are lumps-free [31]. Figure 7(b) shows SEM images of NiS2 nanoparticles with uniform surface morphology at both low and high magnification 

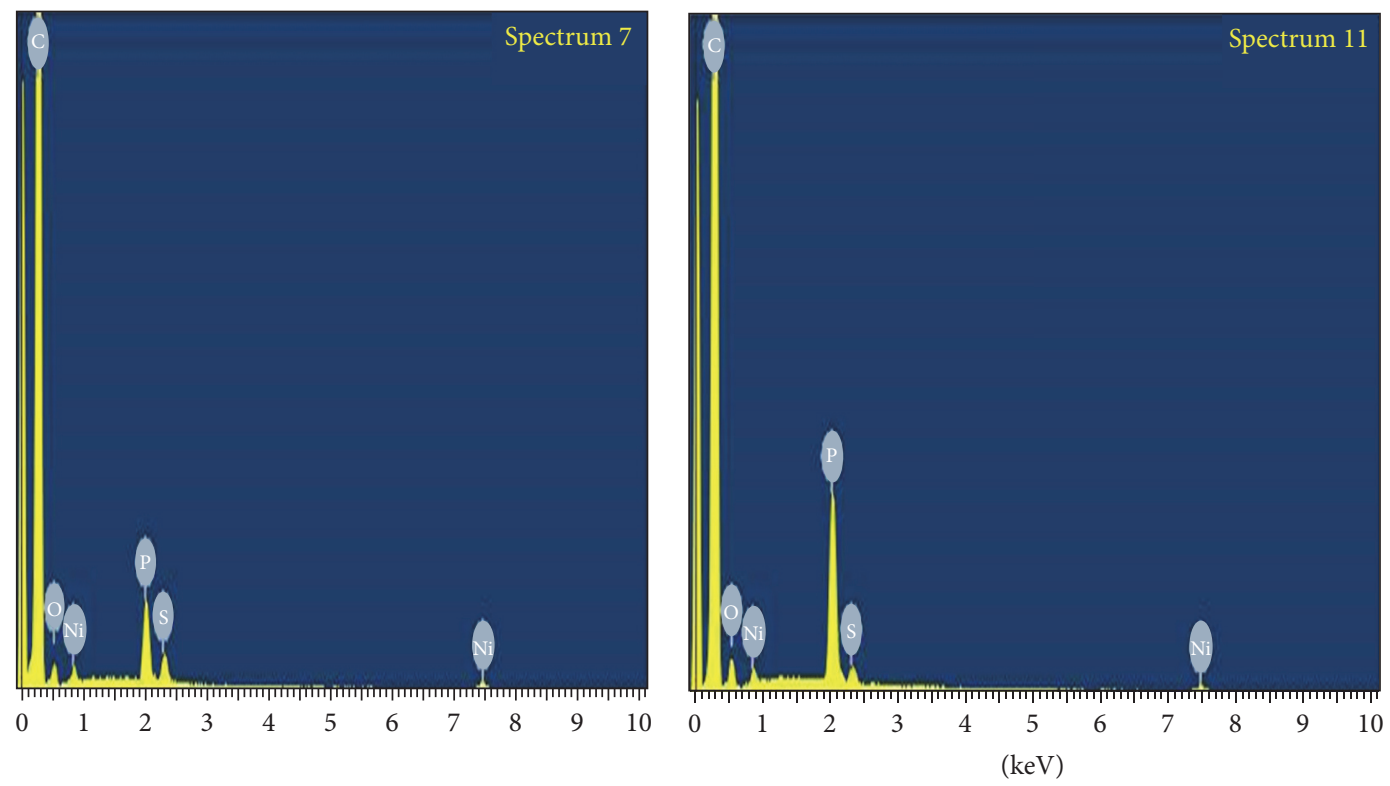

Full-scale 3108 cts. cursor: 0.000

Full-scale 3108 cts. cursor: 0.000

(a)

(b)

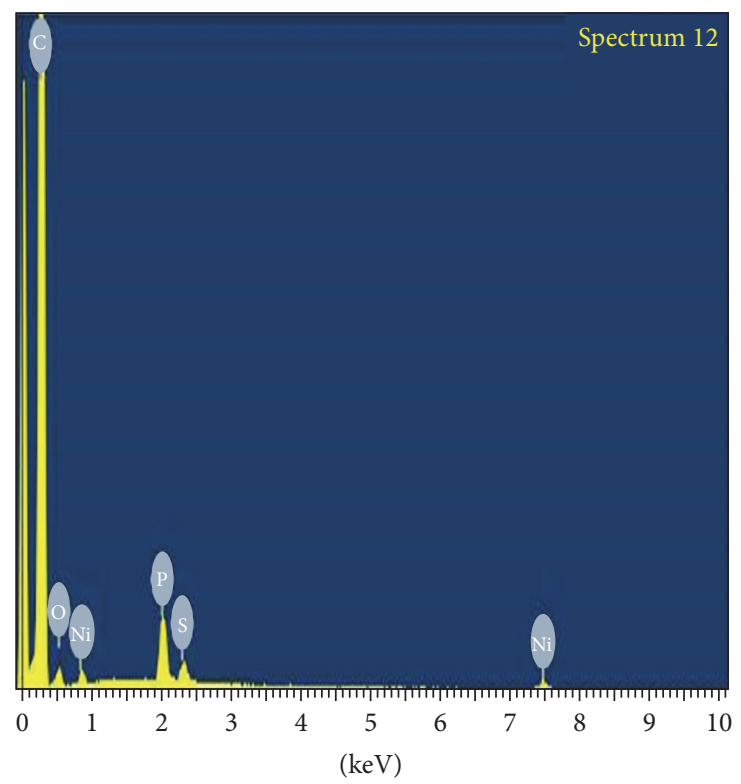

Full-scale 3108 cts. cursor: 0.000

(c)

FIGURE 8: EDS spectra of NiS1 (a), NiS2 (b), and NiS3 (c) of the nanoparticles.

while the SEM images of HDA-capped NiS3 nanoparticles as shown in Figure 7(c) at both low and high magnifications have homogeneous surface morphology with cauliflower-like structures [32]. The EDS spectra of the NiS nanoparticles as presented in Figure 8 confirmed the elemental composition of the NiS nanocrystals. Other traces of elements such as $\mathrm{O}, \mathrm{P}$, and $\mathrm{C}$ are also observed. The observed $\mathrm{P}$ and $\mathrm{O}$ are due to trioctylphosphine (TOP), and $\mathrm{C}$ is attributed to hexadecylamine (HDA) [32].

\section{Conclusion}

$\mathrm{Ni}(\mathrm{II})$ dithiocarbamate complexes have been synthesized and characterized by UV-Vis, FTIR, and NMR spectroscopy. The complexes were formulated as four-coordinate species in which dithiocarbamate acts as bidentate chelating ligand through the sulfur atoms. The complexes were used as single source precursors and thermolysed at $220^{\circ} \mathrm{C}$ to prepare HDAcapped NiS nanoparticles. The absorption spectra studies 
of the as-prepared nanoparticles showed that absorption band edges are blue-shifted compared to the bulk $(\sim 2.1 \mathrm{eV})$ with emission maxima that are red-shifted confirming the small crystallite sizes of the as-prepared nanoparticles. The XRD patterns revealed cubic crystalline phases for the NiS nanocrystals and TEM images showed spherical and closeto-spherical particles with size in the range $12-38 \mathrm{~nm}$ for NiS1, 8-11 $\mathrm{nm}$ for NiS2, and 9-16 $\mathrm{nm}$ for NiS3.

\section{Competing Interests}

The authors declare that there are no competing interests regarding the publication of this paper.

\section{Acknowledgments}

The authors gratefully acknowledge the financial support of Govan Mbeki Research and Development Centre, University of Fort Hare, SASOL, South Africa, and the National Research Foundation/Sasol Inzalo Foundation innovation doctoral scholarship to Azile Nqombolo.

\section{References}

[1] Y. Xia, H. Yang, and C. T. Campbell, "Nanoparticles for catalysis," Accounts of Chemical Research, vol. 46, no. 8, pp. 1671-1672, 2013.

[2] S. Schauermann, N. Nilius, S. Shaikhutdinov, and H.-J. Freund, "Nanoparticles for heterogeneous catalysis: new mechanistic insights," Accounts of Chemical Research, vol. 46, no. 8, pp. 16731681, 2013.

[3] B. S. Sekhon, "Nanotechnology in agri-food production: an overview," Nanotechnology, Science and Applications, vol. 7, no. 2, pp. 31-53, 2014.

[4] J. Li, X. Chen, N. Ai et al., "Silver nanoparticle doped $\mathrm{TiO}_{2}$ nanofiber dye sensitized solar cells," Chemical Physics Letters, vol. 514, no. 1-3, pp. 141-145, 2011.

[5] M. Nie, K. Sun, and D. D. Meng, "Formation of metal nanoparticles by short-distance sputter deposition in a reactive ion etching chamber," Journal of Applied Physics, vol. 106, no. 5, Article ID 054314, 2009.

[6] I. Y. Cha, M. Ahn, S. J. Yoo, and Y.-E. Sung, "Facile synthesis of carbon supported metal nanoparticles via sputtering onto a liquid substrate and their electrochemical application," $R S C$ Advances, vol. 4, no. 73, pp. 38575-38580, 2014.

[7] T. Ahn, J. H. Kim, H.-M. Yang, J. W. Lee, and J.-D. Kim, "Formation pathways of magnetite nanoparticles by coprecipitation method," The Journal of Physical Chemistry C, vol. 116, no. 10, pp. 6069-6076, 2012.

[8] R. M. Alwan, Q. A. Kadhim, K. M. Sahan et al., "Synthesis of zinc oxide nanoparticles via sol-gel route and their characterization," Journal of Nanoscience and Nanotechnology, vol. 5, no. 1, pp. 1-6, 2015.

[9] M. A. Malik, M. Y. Wani, and M. A. Hashim, "Microemulsion method: a novel route to synthesize organic and inorganic nanomaterials. 1st Nano update," Arabian Journal of Chemistry, vol. 5, no. 4, pp. 397-417, 2012.

[10] H. Hayashi and Y. Hakuta, "Hydrothermal synthesis of metal oxide nanoparticles in supercritical water," Materials, vol. 3, no. 7, pp. 3794-3817, 2010.
[11] K. Ramasamy, M. A. Malik, P. O’Brien, and J. Raftery, "Metal complexes of thiobiurets and dithiobiurets: novel single source precursors for metal sulfide thin film nanostructures," Dalton Transactions, vol. 39, no. 6, pp. 1460-1463, 2010.

[12] I. J.-L. Plante, T. W. Zeid, P. Yang, and T. Mokari, "Synthesis of metal sulfide nanomaterials via thermal decomposition of single-source precursors," Journal of Materials Chemistry, vol. 20, no. 32, pp. 6612-6617, 2010.

[13] D. Y. Chae, K. W. Sea, S. S. Lee, S. H. Yoon, and W. Shim, “CdSe thin films grown by MOCVD method using new single-source precursors," Bulletin of the Korean Chemical Society, vol. 27, no. 5, pp. 762-764, 2006.

[14] S. H. Yoon, S. S. Lee, K. W. Seo, and I.-W. Shim, "Preparation of CdS thin films through MOCVD method, using Cd-S singlesource precursors," Bulletin of the Korean Chemical Society, vol. 27, no. 12, pp. 2071-2073, 2006.

[15] A. Singhal, D. P. Dutta, A. K. Tyagi, S. M. Mobin, P. Mathur, and I. Lieberwirth, "Palladium(II)/allylpalladium(II) complexes with xanthate ligands: single-source precursors for the generation of palladium sulfide nanocrystals," Journal of Organometallic Chemistry, vol. 692, no. 23, pp. 5285-5294, 2007.

[16] W.-M. Zhang, Z.-X. Sun, W. Hao, D.-W. Su, and D. J. Vaughan, "Synthesis of size tuneable cadmium sulphide nanoparticles from a single source precursor using ammonia as the solvent," Materials Research Bulletin, vol. 46, no. 12, pp. 2266-2270, 2011.

[17] M. Salavati-Niasari, G. Banaiean-Monfared, H. Emadi, and M. Enhessari, "Synthesis and characterization of nickel sulfide nanoparticles via cyclic microwave radiation," Comptes Rendus Chimie, vol. 16, no. 10, pp. 929-936, 2013.

[18] S. Nagaveena, S. N. Kumar, and C. K. Mahadevan, "Synthesis by a novel method and application of image processing in characterization of nickel sulphide nanoparticles," International Journal of Engineering Research, vol. 3, pp. 1214-1218, 2013.

[19] H. Wang, J.-R. Zhang, X.-N. Zhao, S. Xu, and J.-J. Zhu, "Preparation of copper monosulfide and nickel monosulfide nanoparticles by sonochemical method," Materials Letters, vol. 55, no. 4, pp. 253-258, 2002.

[20] B. Yuan and W. Luan, "Phase-controlled synthesis of nickel sulfide series via solvorthemal method," Functional Materials Letters, vol. 7, article 6, 2014.

[21] S. Devaramani, J. Malleshappa, S. Kempahanumakkagari, R. Thippeswamy, and P. Mahalingappagari, "Synthesis of nickel nitroprusside coordination nanoparticles by simple means: its characterization and use as electrochemical sensor for sulfide estimation in sewage and water samples," International Journal of Electrochemical Science, vol. 9, no. 8, pp. 4692-4708, 2014.

[22] H. Khan, A. Badshah, G. Murtaz et al., "Synthesis, characterization and anticancer studies of mixed ligand dithiocarbamate palladium(II) complexes," European Journal of Medicinal Chemistry, vol. 46, no. 9, pp. 4071-4077, 2011.

[23] Y. Shi, W. Chu, Y. Wang et al., "Synthesis, characterization and cytotoxicity of the $\mathrm{Au}$ (III) complexes with cyclic aminebased dithiocarbamate ligands," Inorganic Chemistry Communications, vol. 30, pp. 178-181, 2013.

[24] V. Vijayanthimala, B. K. Gomathi, and M. Vijaya, "Synthesis, characterization and study of biological application of simple mixed ligand complexes of nickel(II) with morphiline dithiocarbamate and amine such as ethylenediamine, diethylenetriamine and triethylenetetraamine," Research Journal of Pharmaceutical, Biological and Chemical Sciences, vol. 5, no. 3, pp. 18321837, 2014. 
[25] R. M. Jenkins, M. L. Singleton, E. Almaraz, J. H. Reibenspies, and M. Y. Darensbourg, "Imidazole-containing $\left(\mathrm{N}_{3} \mathrm{~S}\right)$ $\mathrm{Ni}^{\mathrm{II}}$ complexes relating to nickel containing biomolecules," Inorganic Chemistry, vol. 48, no. 15, pp. 7280-7293, 2009.

[26] S. C. Bajia and A. Mishra, "Synthesis and spectroscopic characterization of bis( $N$-alkyldithiocarbamato)nickel(II) complexes: crystal structures of $\left[\mathrm{Ni}\left(\mathrm{S}_{2} \mathrm{CNH}(n-\mathrm{Pr})\right)_{2}\right]$ and $\left[\mathrm{Ni}\left(\mathrm{S}_{2} \mathrm{CNH}(i-\right.\right.$ $\mathrm{Pr}))_{2}$ ], Journal of Coordination Chemistry, vol. 64, no. 15, pp. 2727-2734, 2011.

[27] M. Banerjee, L. Chongad, and A. Sharma, "Structural and optical properties of pure and copper doped NiS nanoparticles," Research Journal of Recent Sciences, vol. 2, pp. 326-329, 2013.

[28] N. Sahiner, K. Sel, K. Meral et al., "Hydrogel templated CdS quantum dots synthesis and their characterization," Colloids and Surfaces A: Physicochemical and Engineering Aspects, vol. 389, no. 1-3, pp. 6-11, 2011.

[29] M. A. Laguna, V. Paillard, B. Kohn et al., "Optical properties of nanocrystalline silicon thin films produced by size-selected cluster beam deposition," Journal of Luminescence, vol. 80, no. 1-4, pp. 223-228, 1998.

[30] H. R. Pouretedal, "Momenzadeh, synthesis, characterization and study of photocatalytic activity of nanocomposites of oxides and sulphides of $\mathrm{Ni}(\mathrm{II})$ and $\mathrm{Ni}(\mathrm{III})$," Bulgarian Chemical Communications, vol. 11, pp. 59-65, 2015.

[31] Z. Yang, A. B. Smetana, C. M. Sorensen, and K. J. Klabunde, "Synthesis and characterization of a new tiara Pd(II) thiolate complex, $\left[\mathrm{Pd}\left(\mathrm{SC}_{12} \mathrm{H}_{25}\right)_{2}\right]_{6}$, and its solution-phase thermolysis to prepare nearly monodisperse palladium sulfide nanoparticles," Inorganic Chemistry, vol. 46, no. 7, pp. 2427-2431, 2007.

[32] Y. Fazli, S. M. Pourmortazavi, I. Kohsari, and M. Sadeghpur, "Electrochemical synthesis and structure characterization of nickel sulfide nanoparticles," Materials Science in Semiconductor Processing, vol. 27, no. 1, pp. 362-367, 2014. 

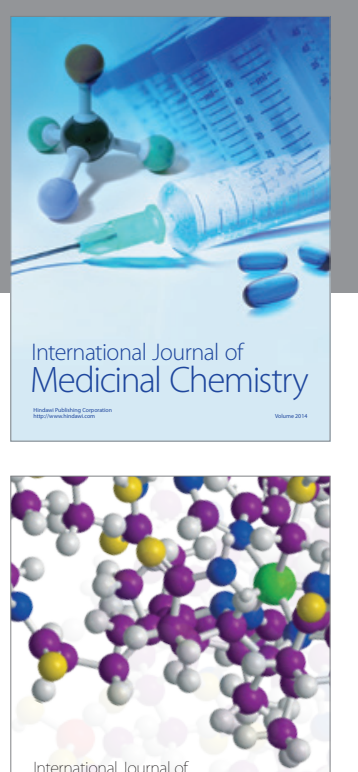

Carbohydrate Chemistry

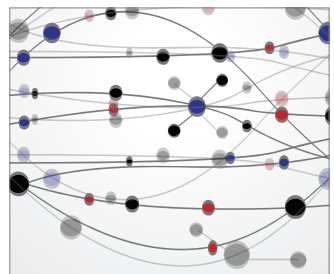

The Scientific World Journal
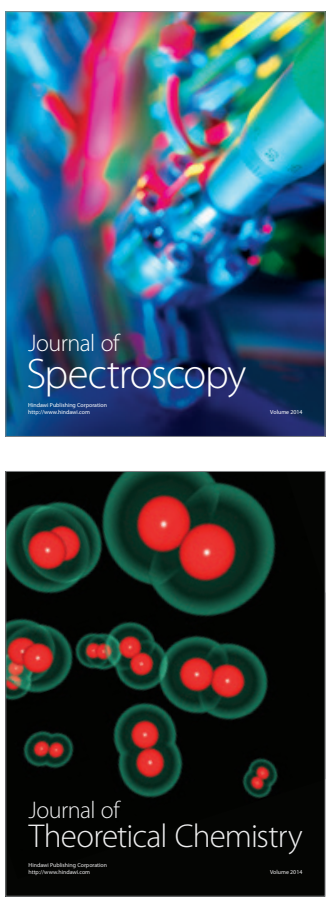
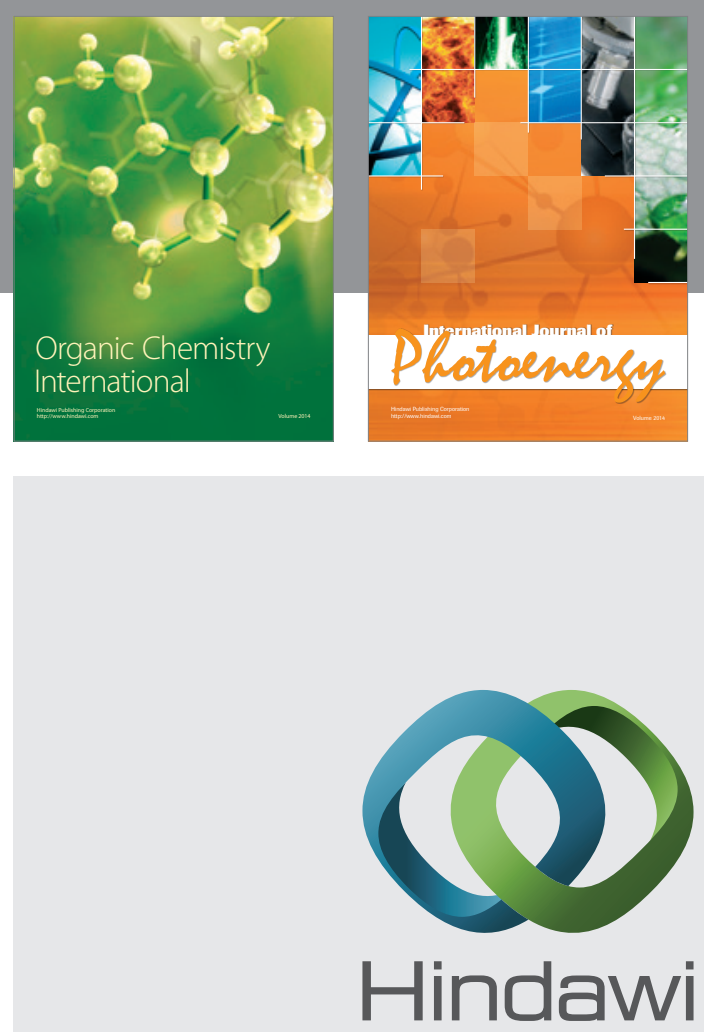

Submit your manuscripts at

http://www.hindawi.com

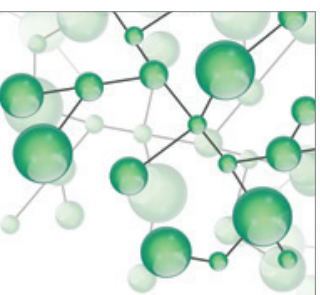

International Journal of

Inorganic Chemistry

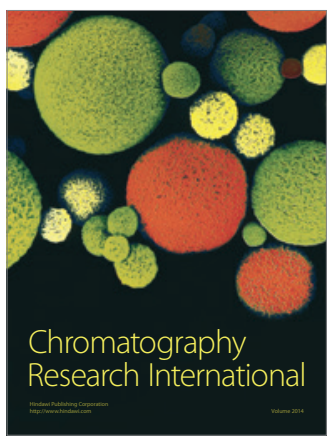

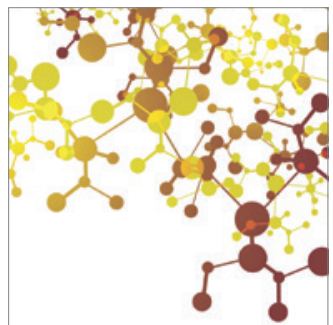

Applied Chemistry
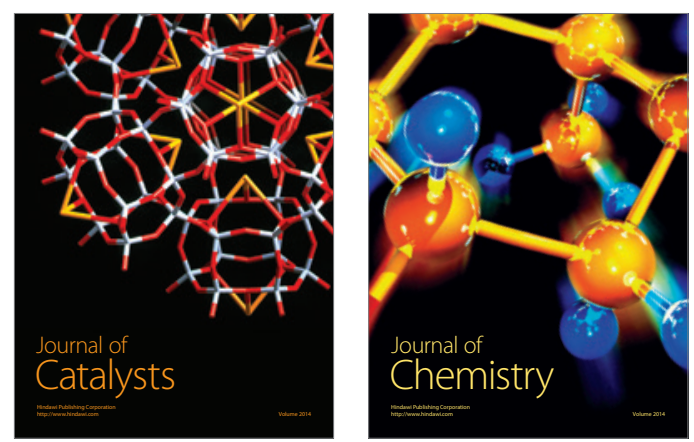
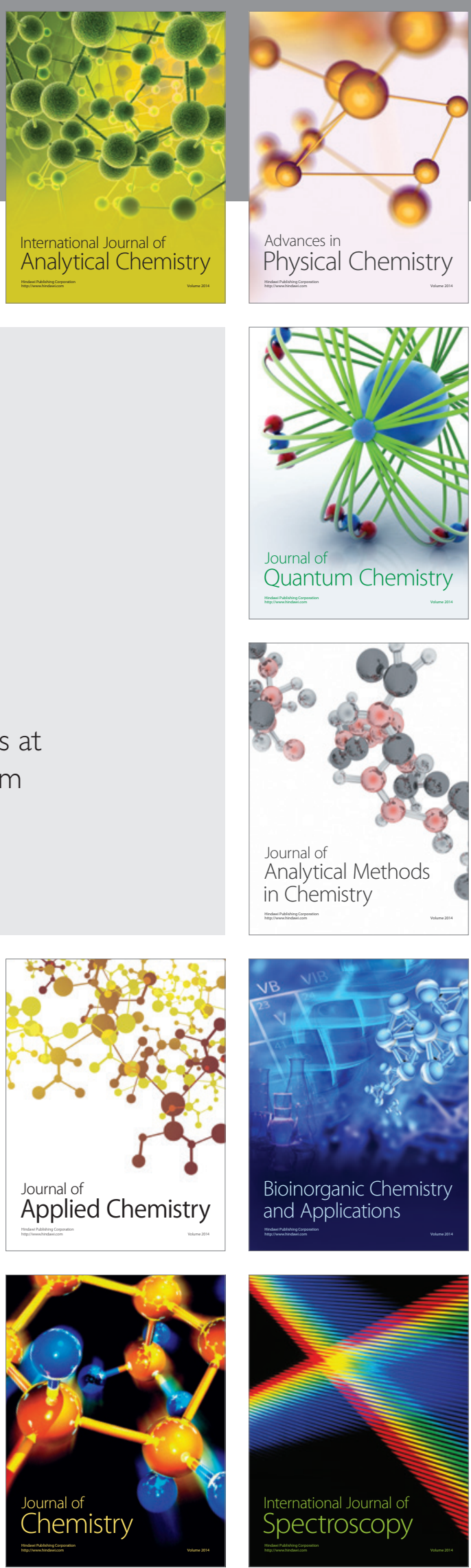